Research Article

\title{
Analysis of the Physical Behavior of the Periodic Mixed-Convection Flow around a Nonconducting Horizontal Circular Cylinder Embedded in a Porous Medium
}

\author{
Muhammad Ashraf, ${ }^{1}$ Zia Ullah,, Saqib Zia, ${ }^{2}$ Sayer O. Alharbi, ${ }^{3}$ \\ Dumitru Baleanu $\mathbb{D}^{4,5,6}$ and Ilyas Khan $\mathbb{D}^{3}$ \\ ${ }^{1}$ Department of Mathematics, Faculty of Science, University of Sargodha, Sargodha 40100, Pakistan \\ ${ }^{2}$ Department of Mathematics, COMSATS University Islamabad, Islamabad 44000, Pakistan \\ ${ }^{3}$ Department of Mathematics, College of Science Al-Zulfi, Majmaah University, Al-Majmaah 11952, Saudi Arabia \\ ${ }^{4}$ Department of Mathematics, Cankaya University, Ankara 06790, Turkey \\ ${ }^{5}$ Institute of Space Sciences, 077125 Magurele, Romania \\ ${ }^{6}$ Department of Medical Research, China Medical University Hospital, China Medical University, Taichung 40447, Taiwan
}

Correspondence should be addressed to Dumitru Baleanu; baleanu@mail.cmuh.org.tw and Ilyas Khan; i.said@mu.edu.sa

Received 25 September 2020; Revised 24 November 2020; Accepted 13 January 2021; Published 25 January 2021

Academic Editor: Hijaz Ahmad

Copyright (c) 2021 Muhammad Ashraf et al. This is an open access article distributed under the Creative Commons Attribution License, which permits unrestricted use, distribution, and reproduction in any medium, provided the original work is properly cited.

\begin{abstract}
An oscillatory mixed-convection fluid flow mechanism across a nonconducting horizontal circular cylinder embedded in a porous medium has been computed. For this purpose, a model in the form of partial differential equations is formulated, and then, the governing equations of the dimensionless model are transformed into the primitive form for integration by using primitive variable formulation. The impact of emerging parameters such as porous medium parameter $\Omega$, Richardson number $\lambda$, magnetic force parameter $\xi$, and Prandtl number Pr on skin friction, heat transfer, and current density is interpreted graphically. It is demonstrated that accurate numerical results can be obtained by the present method by treating nonoscillating and oscillating parts of coupled partial differential equations simultaneously. In this study, it is well established that the transient convective heat transfer, skin friction, and current density depend on amplitude and phase angle. One of the objects of the present study is to predict the mechanism of heat and fluid flow around different angles of a nonconducting horizontal circular cylinder embedded in a porous medium.
\end{abstract}

\section{Introduction}

The mixed convection mechanism and thermally driven flow in a porous medium have important applications in utilizing geothermal energy, industrial process, and mechanical, civil, and chemical engineering. Moreover, in insulation materials, the flow of helium in pebble-bed nuclear reactors, underground disposal of nuclear or nonnuclear waste, food processing and storage, metallurgy, crude oil extraction, flow in the eye of glaucoma patients, and flow through filtering media are important examples of fluid flows in the porous medium. Porous medium effects cause resistance to the fluid flow due to the difference between the viscosity of a porous medium and the fluid. In the view of these applications, Joshi and Gebhart [1] presented a technical note on the mixed-convection mechanism through heat flux surface with a porous medium by using Hamming's predictor-corrector method. The heat and fluid flow mechanism over a flat plate which is placed in a porous medium has been performed in Hossain et al.'s study [2]. They used Keller box technique to obtain numerical results with free-stream velocity and small amplitude variations in the wall temperature. The effect of transverse magnetic field on mixed-convection phenomena over a semi-infinite permeable vertical plate in a porous medium at constant heat flux has been 
studied by Chamkha [3]. Later, Chamkha et al. [4] proposed a nonsimilar boundary-layer problem for the natural convection flow around an isothermal sphere placed in a saturated porous medium.

The mixed-convection boundary-layer flow considering $\mathrm{Cu}, \mathrm{Al}_{2} \mathrm{O}_{3}$, and $\mathrm{TiO}_{2}$ as a nanoparticles in the base fluid along the heat and cooled cylinder has been investigated in Nazar et al.'s study [5]. Gorla et al. [6] discussed a boundary layer phenomenon of the mixed convection flow of the nanofluid past a vertical wedge that is placed in a porous medium theoretically. Cimpean and Pop [7] studied the effect of a porous medium on the fully developed mixedconvection flow along a channel for the saturated nanofluid. Imran et al. [8] presented an analysis of mixed-convection unsteady flow over a stretching vertical sheet placed in a porous medium with a heat source. Sumaily and Thomson [9] studied a steady and pulsating forced-convection flow around a circular cylinder placed in an empty or porous medium and concluded that heat transfer enhances due to the porous medium. Hayat et al. [10] analyzed a mixedconvection flow mechanism over a porous sheet in the presence of convective boundary conditions with variable thermal conductivity effects. They examined similar effects of velocity and temperature profiles in the qualitative sense. Darcy and porous particle diameter-affected heat transfer rate in the cavity has been computed by Behzadi et al. in [11].

Ullah et al. [12] considered a magnetohydrodynamic mixed-convection flow of Casson fluid past a wedge by assuming that the wedge is moving inside a porous medium with the effects of convective boundary conditions and chemical reaction numerically. Yadav and Singh [13] considered a transient flow mechanism around a circular cylinder that was filled with porous material. They observed that the velocity gradient decreases slowly from the boundary to the central region of the cylinder for large values of the viscosity ratio. Ashraf and Fatima [14] discussed the effect of viscous dissipation on the transient flow to obtain numerical solutions around different stations of the sphere. Garg et al. [15] examined the convective boundary-condition outcomes on the unsteady MHD flow over a porous plate in the slip-flow regime. Ashraf et al. $[16,17]$ performed the natural convection mechanism on different shapes numerically. Rashad et al. [18] investigated the heat transfer problem by means of micropolar nanofluids past a cylinder in the presence of a saturated porous medium. They obtained oscillatory behavior of microrotation velocity for large values of the material parameter $\Delta$.

Rashad et al. [19] illustrated the heat transfer behavior of the mixed convection flow of a water-copper nanofluid around different positions of the trapezoidal enclosure that is consigned in a porous medium with variable properties. The variable density effect on an oscillatory fluid flow mechanism around a nonconducting shape has been investigated by Ashraf and Ullah in [20], and then they performed magnetothermo analysis in [21]. Recently, Ullah et al. [22] computed an oscillatory flow model across a nonconducting shape embedded in a thermally stratified medium. They depicted the considerable fluctuating response in heat transport for large value of Prandtl number.
Taking idea from the current literature review, it is illustrated that the oscillatory mixed-convection fluid flow around a nonconducting horizontal circular cylinder embedded in a porous medium has not yet been computed in the literature. By following the current literature $[2,18]$, we establish a mathematical model in terms of coupled nonlinear partial differential equation to highlight the physical behavior of the oscillatory mixed-convection flow across a circular cylinder embedded in a porous medium. Later, we will solve this model by using the very accurate numerical scheme finite difference method. We explore the effects of different parameters included in the flow model on skin friction $\tau_{w}$, heat transfer $q_{w}$, and current density $j_{w}$.

\section{Governing Equations and Problem Formulation}

Considering a two-dimensional, unsteady, viscous, and incompressible boundary-layer fluid flow phenomenon across a nonconducting horizontal circular cylinder embedded in a porous medium, as shown in Figure 1, here, the coordinate system $(x, y)$ represents the distance along the surface and normal to the surface, respectively. We assume the magnetic field coordinate system $\left(H_{x}, H_{y}\right)$ along the surface and normal to the surface, respectively, where $T$ is the temperature variable throughout the assumed domain. We establish the concept of oscillatory by assuming external fluid velocity as $u=U(\tau)$, far from the surface of the domain. Moreover, to justify our claim of given phenomena, we assume the effect of the magnetic field from outreach to the surface of the cylinder. By following the current literature [18], we extend this work to highlight the physical behavior of the oscillatory mixedconvection flow across a circular cylinder embedded in a porous medium. In keeping view of the constraint of the length of the article, we assume the set of the coupled nonlinear dimensionless system of partial differential equations as given as follows:

$$
\begin{gathered}
\frac{\partial \bar{u}}{\partial \bar{x}}+\frac{\partial \bar{v}}{\partial \bar{y}}=0, \\
\frac{\partial \bar{u}}{\partial \tau}+\bar{u} \frac{\partial \bar{u}}{\partial \bar{x}}+\bar{v} \frac{\partial \bar{u}}{\partial \bar{y}}=\frac{\partial^{2} \bar{u}}{\partial \bar{y}^{2}}+\xi\left(\bar{h}_{x} \frac{\partial \bar{h}_{x}}{\partial \bar{y}}+\bar{h}_{y} \frac{\partial \bar{h}_{x}}{\partial \bar{y}}\right) \\
+\Omega(1-\bar{u})+\lambda \bar{\theta} \sin \alpha, \\
\frac{\partial \bar{h}}{\partial \bar{x}}+\frac{\partial \bar{h}_{y}}{\partial \bar{y}}=0, \\
+\bar{u} \frac{\partial \bar{h}}{\partial \bar{x}}+\bar{v} \frac{\partial \bar{h}}{\partial \bar{y}}-\bar{h}_{x} \frac{\partial \bar{u}}{\partial \bar{x}}-\bar{h}_{y} \frac{\partial \bar{u}}{\partial \bar{y}}=\frac{1}{\gamma} \frac{\partial^{2} \bar{h}}{\partial \bar{y}^{2}} \\
\frac{\partial \bar{\theta}}{\partial \tau}+\bar{u} \frac{\partial \bar{\theta}}{\partial \bar{x}}+\bar{v} \frac{\partial \bar{\theta}}{\partial \bar{y}}=\frac{1}{P_{r}} \frac{\partial^{2} \bar{\theta}}{\partial \bar{y}^{2}} .
\end{gathered}
$$

The dimensionalized selected boundary conditions are given as follows: 


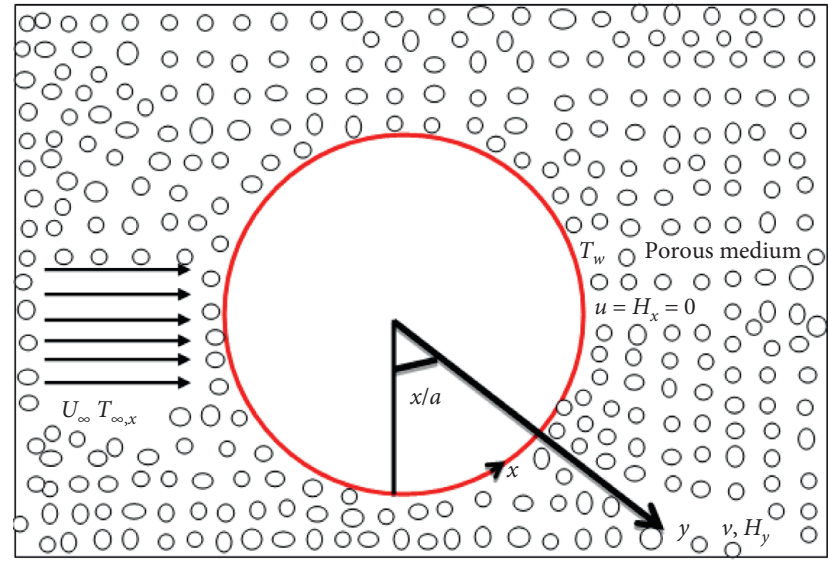

Figure 1: Geometry of the flow process.

$$
\begin{aligned}
\bar{u} & =\bar{v}=0, \\
\bar{h}_{y} & =\bar{h}_{x}=0, \\
\bar{\theta} & =1 \text { at } \bar{y}=0, \\
\bar{u} & \longrightarrow \bar{U}(\tau), \\
\bar{\theta} & \longrightarrow 0, \\
\bar{h}_{y} & \longrightarrow 1 \text { as } \bar{y} \longrightarrow \infty .
\end{aligned}
$$

In equations (1)-(6), $\xi$ is the magnetic force parameter, the Richardson number is $\lambda$, the magnetic Prandtl number is $\gamma$, the Prandtl parameter is $\operatorname{Pr}, \Omega$ is the permeability parameter (the porous medium parameter), $D_{a_{L}}$ is the Darcy number, $R_{e_{L}}$ is Reynold's number, $\theta$ is the dimensionless fluid temperature, and $\varepsilon^{+}$represents the porosity of the medium. We take the stream velocity equation as $U(\tau)=1+\varepsilon e^{i \omega \tau}$ and $|\varepsilon| \ll 1$, in which $\varepsilon$ is the oscillating condition of small magnitude and the parameter $\omega$ is the frequency parameter. The velocity, magnetic field, and temperature components are $u, v, h_{x}, h_{y}$, and $\theta$ in the sum form of nonoscillating and oscillating parts given as follows:

$$
\begin{aligned}
\bar{u} & =u_{s}+\varepsilon u_{t} e^{i \omega \tau}, \\
\bar{v} & =v_{s}+\varepsilon v_{t} e^{i \omega \tau}, \\
\bar{h}_{x} & =h_{x s}+\varepsilon h_{x t} e^{i \omega \tau}, \\
\bar{h}_{y} & =h_{y s}+\varepsilon h_{y t} e^{i \omega \tau}, \\
\bar{\theta} & =\theta_{s}+\varepsilon \theta_{t} e^{i \omega \tau} .
\end{aligned}
$$

We substitute (7) into equations (1)-(5) along with boundary conditions (6). Then, by following Ashraf and Ullah [20], we separate nonoscillating and oscillating components of the order analysis subject to $O\left(\varepsilon^{0}\right)$ and $O\left(\varepsilon e^{i \omega \tau}\right)$. Later, by following Ullah et al.'s work [21], we use primitive variable formulation to obtain nonoscillating and oscillating parts of the primitive coupled nonlinear PDEs.

\section{Computational Technique}

As discussed in the preceding paragraph, the obtained form of the primitive system of the nonoscillating and oscillating differential equation is solved numerically by adopting the finite difference method. First, we solve the nonoscillating part, and then, obtained results are used in the oscillating part to overcome the nonlinearity involved in the system of equations. From the difference form of each equation, we obtained the system of algebraic equations. This system of algebraic equation has coefficient tridiagonal matrix and unknown variables $U, V, \theta$, and $\varphi$. In keeping view of the structure of the coefficient matrix, we use the Gaussian elimination technique to find the values of unknown variables. Once we secure values of these variables, we use these values to determine the oscillatory form of skin friction $\tau_{w}$, heat transfer $q_{w}$, and current density $j_{w}$ with the help of the following expression:

$$
\begin{aligned}
\tau_{w} & =\left(\frac{\partial U}{\partial Y}\right)_{y=0}+\varepsilon\left|A_{s}\right| \cos \left(\omega t+\alpha_{s}\right), \\
q_{w} & =\left(\frac{\partial \theta}{\partial Y}\right)_{y=0}+\varepsilon\left|A_{t}\right| \cos \left(\omega t+\alpha_{t}\right), \\
j_{w} & =\left(\frac{\partial \varphi}{\partial Y}\right)_{y=0}+\varepsilon\left|A_{m}\right| \cos \left(\omega t+\alpha_{m}\right), \\
A_{s} & =\left(u_{1}^{2}+u_{2}^{2}\right)^{(1 / 2)} \\
A_{t} & =\left(\theta_{1}^{2}+\theta_{2}^{2}\right)^{(1 / 2)} \\
A_{m} & =\left(\varphi_{x 1}^{2}+\varphi_{x 2}^{2}\right) \\
\alpha_{s} & =\tan ^{-1}\left(\frac{u_{2}}{u_{1}}\right) \\
\alpha_{m} & =\tan ^{-1}\left(\frac{\varphi_{x 2}}{\varphi_{x 1}}\right) \\
\alpha_{t} & =\tan ^{-1}\left(\frac{\theta_{2}}{\theta_{1}}\right)
\end{aligned}
$$

where $u_{1}$ and $u_{2}$ are real and imaginary parts of velocity, $\theta_{1}$ and $\theta_{2}$ are the real and imaginary parts of temperature, and $\varphi_{x 1}$ and $\varphi_{x 2}$ are the real and imaginary parts of the magnetic field, respectively. Moreover, $A_{s}, A_{t}$, and $A_{m}$ are amplitudes, while $\alpha_{s}, \alpha_{t}$, and $\alpha_{m}$ are phase angles in the abovementioned mechanism.

\section{Results and Discussion}

The current work is addressed on an oscillatory mixedconvection fluid flow mechanism for the viscous and incompressible fluid across a nonconducting horizontal circular cylinder embedded in a porous medium. Here, we 

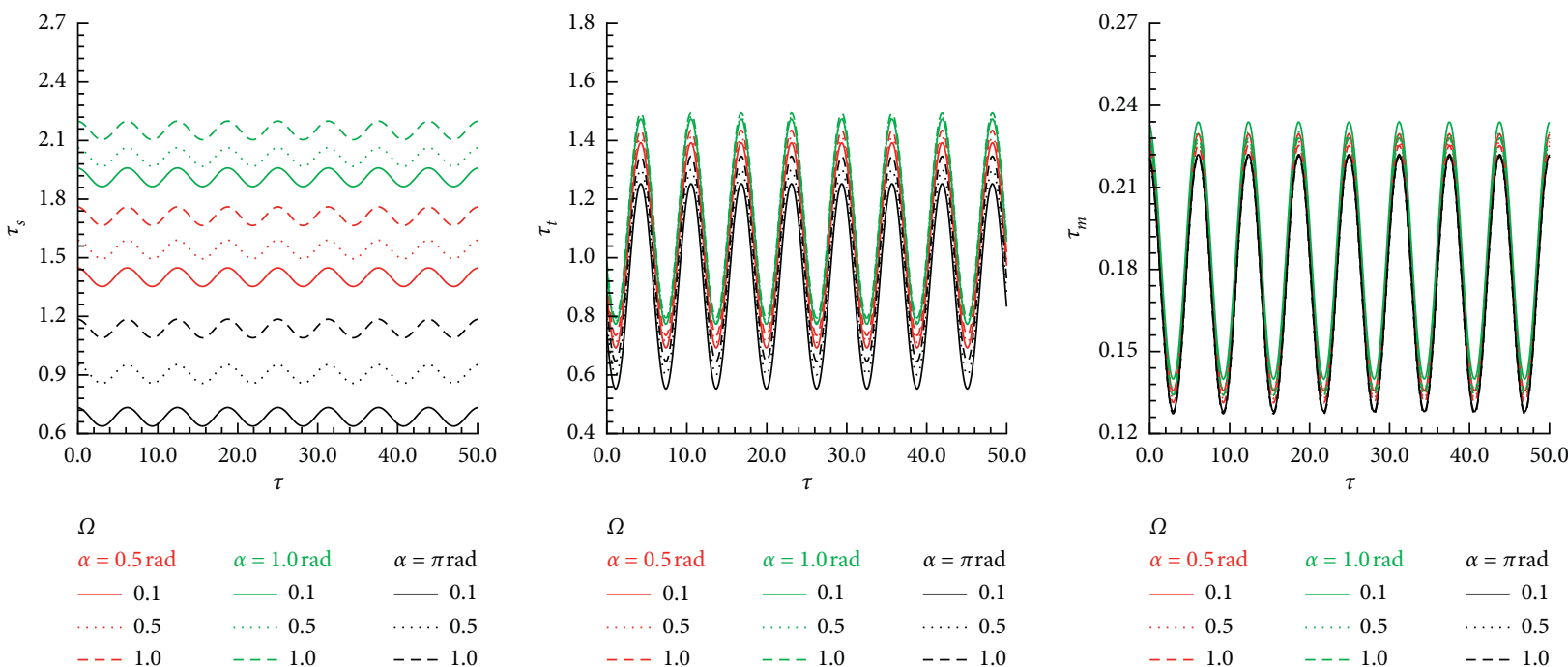

(a)

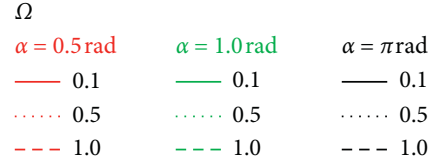

(b)

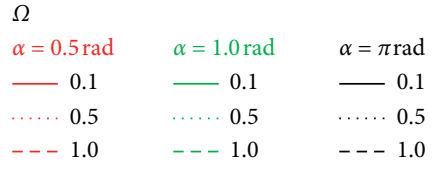

(c)

Figure 2: The physical profiles for (a) $\tau_{w}$, (b) $q_{w}$, and (c) $j_{w}$ at positions $\alpha=0.5,1.0$, and $\pi$ with three values of the porous medium parameter $\Omega=0.1,0.5$, and 1.0 where others are $\gamma=0.1, \operatorname{Pr}=7.0, \xi=1.0$, and $\lambda=3.5$.

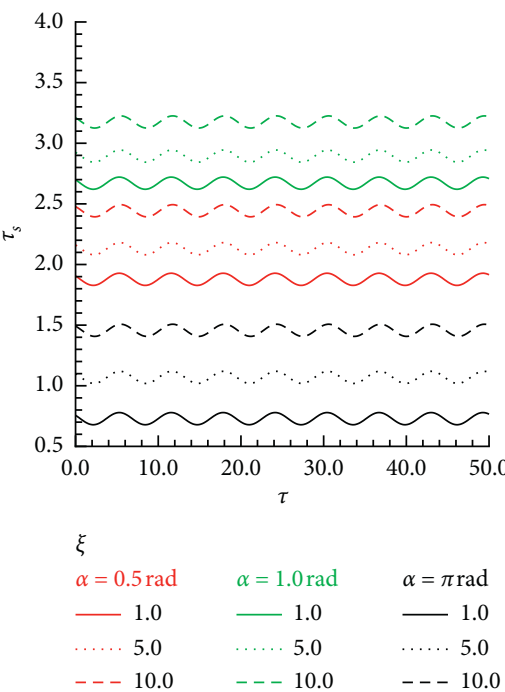

(a)

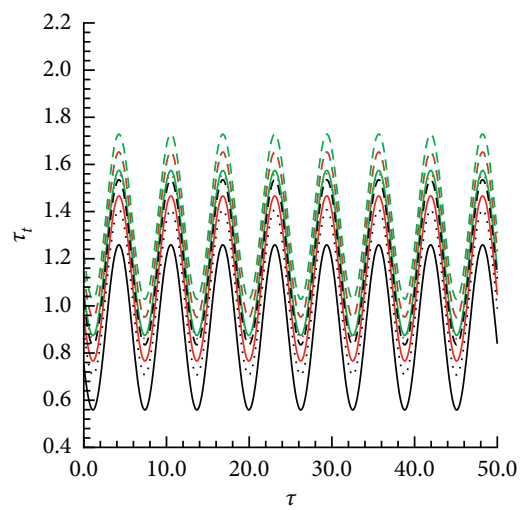

$\xi$

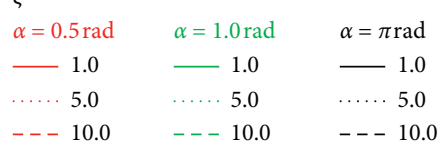

(b)
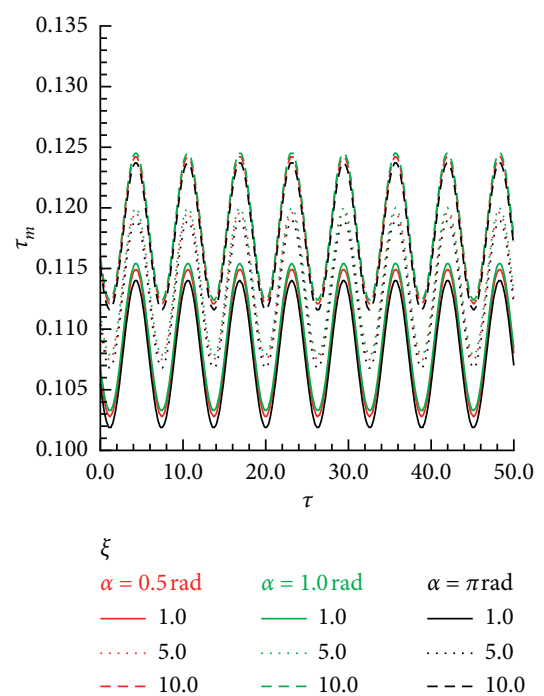

(c)

FIgURe 3: The physical profiles for (a) $\tau_{w}$, (b) $q_{w}$, and (c) $j_{w}$ at positions $\alpha=0.5,1.0$, and $\pi$ with three values of $\xi=1.0,5.0$, and 10.0 where others are $\gamma=0.01, \operatorname{Pr}=7.0, \Omega=0.1$, and $\lambda=6.0$.

precisely thrashed out the substantial effect of emerging parameters graphically within the prescribed boundary conditions. We examine the effect of all parameters on skin friction $\tau_{w}$, heat transfer $q_{w}$, and current density $j_{w}$ across three different stations of the cylinder. Here, we accord the numerical solution for the effects of all parameters engaged in the flow model gradually.

Figures 2(a)-2(c) are presented to illustrate the oscillating behavior of $\tau_{w}, q_{w}$, and $j_{w}$ for three selected values of $\Omega=0.1,0.5$, and 1.0 at $\alpha=0.5,1.0$, and $\pi$ position for $\operatorname{Pr}=7.0$. In Figure 2(a), the small amplitude of skin friction with distinct variations at each station is obtained, respectively. Figure 2(b) depicts that an enhancement in oscillation of heat transfer with a similar trend is obtained for lower $\Omega=0.1$ at each angle. The fluctuating behavior in current density is uniformly distributed with high amplitude at each station $\alpha=0.5,1.0$, and $\pi$ in the presence of $\Omega$ for $\operatorname{Pr}=7.0$ in Figure 2(c). Increasing $\Omega$ means the medium is more porous and the fluid permeability in the porous layer is increased and thus yields the resistance in the fluid flow. However, due to the strong Richardson number $\lambda$ which acts like a pressure gradient and dominated over the resistance, skin friction is increased and slight changes in $q_{w}$ and $j_{w}$ are noted. Figure 3(a) shows the effects of the magnetic force parameter $\xi$ on all abovementioned physical quantities. In this plot, it is noted that an increment in $\xi$ 

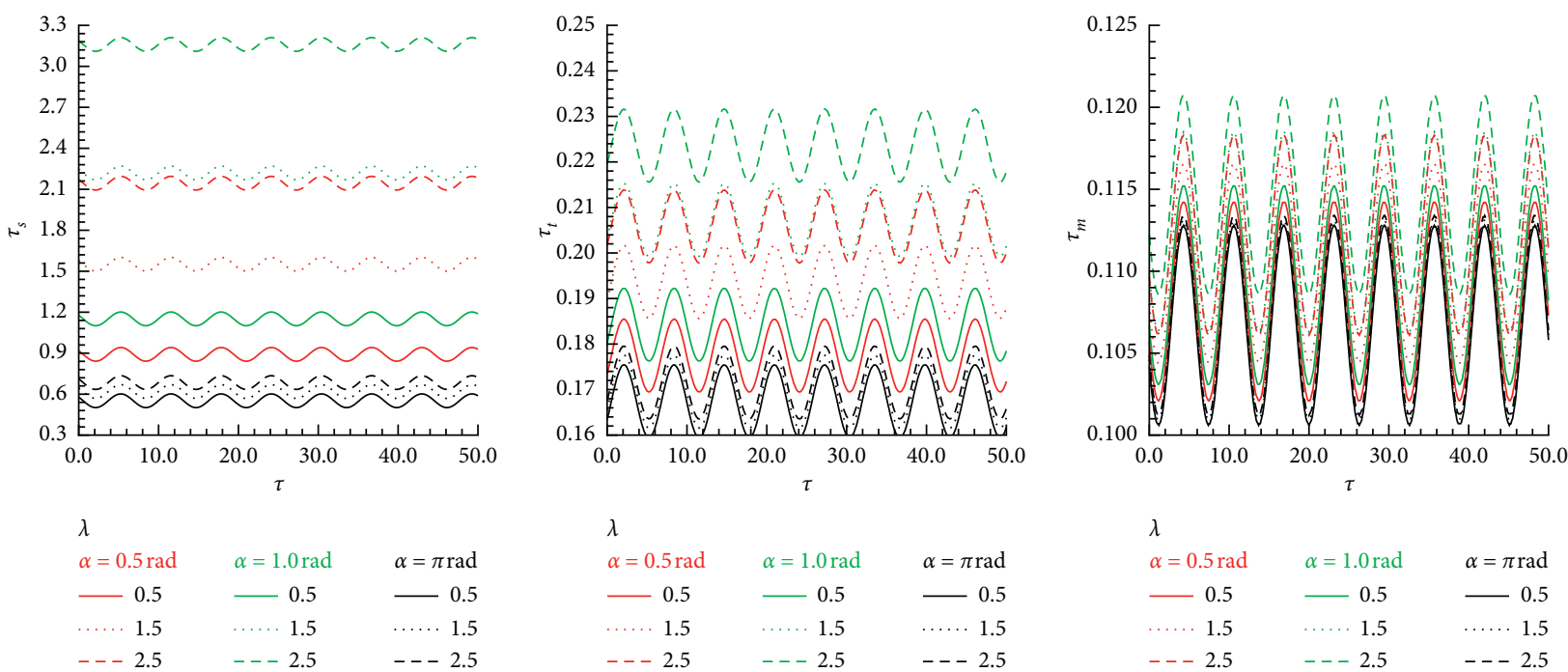

(a)

(b)

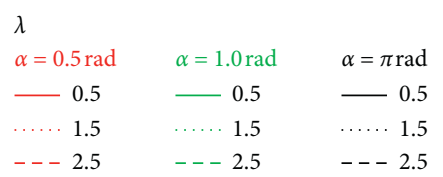

(c)

Figure 4: The physical profiles for (a) $\tau_{w}$, (b) $q_{w}$, and (c) $j_{w}$ at positions $\alpha=0.5,1.0$, and $\pi$ with three values of $\lambda=0.5$, 1.5 , and 2.5 where others are $\gamma=0.01, \operatorname{Pr}=0.1, \xi=0.2$, and $\Omega=0.1$.
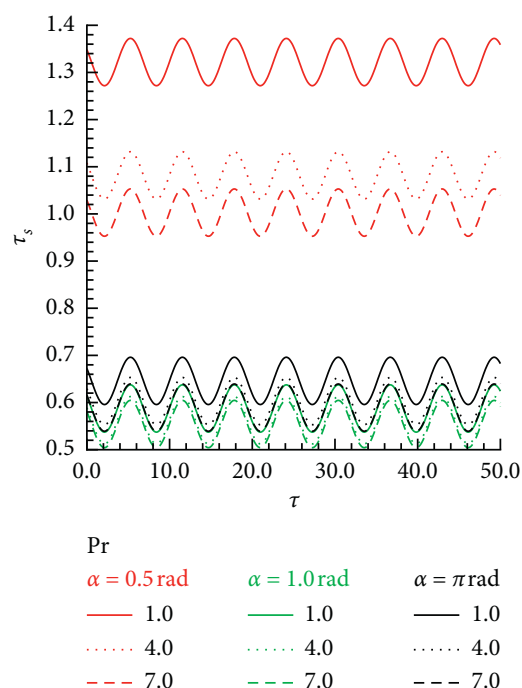

(a)
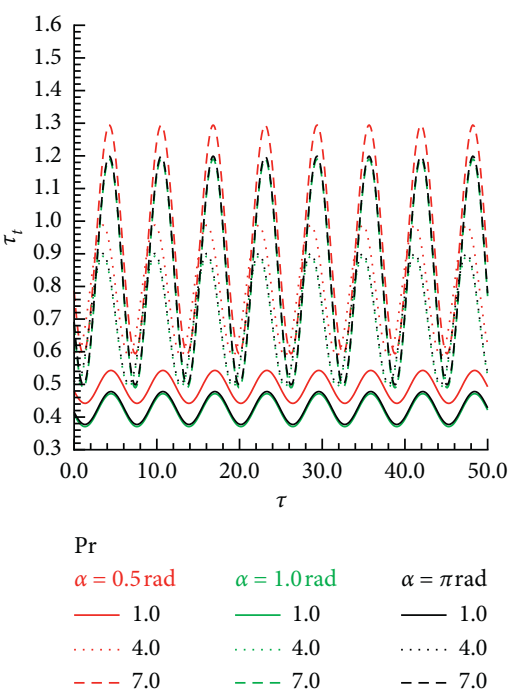

(b)

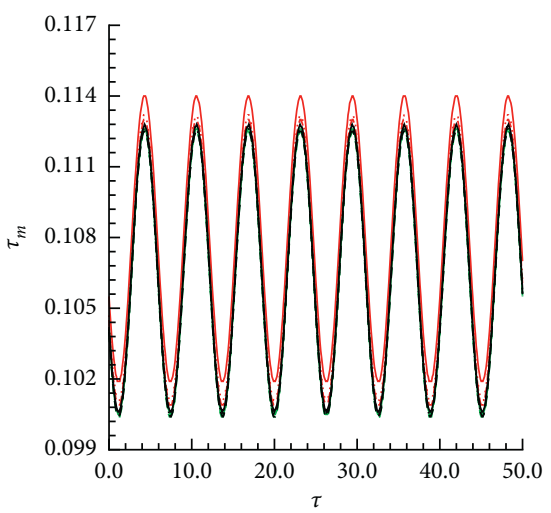

$\operatorname{Pr}$

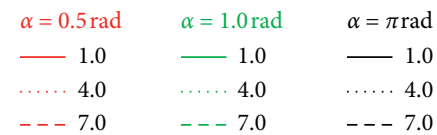

(c)

Figure 5: The physical profiles for (a) $\tau_{w}$, (b) $q_{w}$, and (c) $j_{w}$ at positions $\alpha=0.5,1.0$, and $\pi$ with three values of $\operatorname{Pr}=1.0,4.0$, and 7.0 where others are $\gamma=0.01, \lambda=2.0, \xi=0.1$, and $\Omega=0.1$.

causes reduction in skin friction. Figure 3(b) describes the higher oscillation in heat transfer with the same variation in $\xi$ as observed in Figure 3(a). With increasing values of $\xi$ that enhanced the Lorentz forces which opposes the flow and generates the current in fluid layers. Thus, Lorentz forces increase the friction between the layers of the fluid which yields an increment in $q_{w}$ and $j_{w}$ in Figure 3(c). In Figure 4(a), we claim that the increase in Richardson number $\lambda$ has same oscillating effects on $\tau_{w}$ at each position. The maximum oscillations in $q_{w}$ and $j_{w}$ at the position with good variations are examined in Figures 4(b) and 4(c). The large value of Richardson number $\lambda$ acts like a pressure gradient to increase the motion of the fluid that causes an increase in $q_{w}$ and $j_{w}$. The impact of different values of Prandtl number Pr is highlighted for oscillating skin friction in Figure 5(a). The fluctuations in $\tau_{w}$ are deliberated in the prominent form, and good variations are obtained at $\alpha=1.0$ and $\pi$ station. The minimum amplitude in heat transfer for lower $\operatorname{Pr}=1.0$ is noted, but good amplitude with certain height is plotted for large $\mathrm{Pr}=7.0$ at each station in Figure 5(b). The current density with prominent amplitude at each position is depicted in Figure 5(c). Also, it is highlighted that the fluctuation of $q_{w}$ increases as $\operatorname{Pr}$ is increased, but mild variation in current density is observed. The most favorable position is $\alpha=1.0$ for all oscillating results in the abovesaid mechanism. 


\section{Conclusions}

The current work is based on an oscillatory mixed-convection heat transfer mechanism for the viscous and incompressible electrically conducting fluid across a nonconducting horizontal circular cylinder embedded in a porous medium. The dimensionless model is converted into the primitive form by applying primitive variable formulation. The final primitive formed equations are solved with the help of the implicit finite difference method. The oscillatory skin friction $\tau_{w}$, heat transfer $q_{w}$, and current density $j_{w}$ are displayed around different $\alpha=0.5,1.0$, and $\pi$ positions of the cylinder for various physical parameters graphically.

(1 ) The small amplitude of oscillation in skin friction is noted at each station for each physical parameter, but prominent fluctuations are examined in heat transfer and current density

(2) The oscillating behavior in current density is uniformly distributed at each station $\alpha=0.5,1.0$, and $\pi$ for each value of the porous medium parameter and Prandtl number

(3) The prominent oscillating response in heat transfer and current density is noted with good variations for each value of the mixed convection parameter $\lambda$ at each station

(4) The large value of the parameter $\lambda$ acts like a pressure gradient to increase the motion of the fluid which caused an increase in $q_{w}$ and $j_{w}$ and dominance over porosity

(5) The maximum fluctuation in heat transfer is obtained for large values of Prandtl number $\operatorname{Pr}=4.0$ and 7.0 at each position of the nonconducting cylinder

(6) The most favorable position for prominent amplitude and maximum value of heat transfer and current density is $\alpha=1.0$ radian

\section{Nomenclature}

$T_{\infty}:$ Ambient temperature (K)

$R_{e_{L}}$ : Reynold's number

$v: \quad$ Kinematic viscosity $\left(\mathrm{m}^{2} \mathrm{~s}^{-1}\right)$

$G_{r_{L}}:$ Grashof number

$\sigma: \quad$ Electrical conductivity $\left(\mathrm{s} \mathrm{m}^{-1}\right)$

$C_{p}:$ Specific heat $\left(\mathrm{J} \mathrm{kg}^{-1} \mathrm{~K}^{-1}\right)$

$\mu$ : Dynamic viscosity $\left(\mathrm{kg} \mathrm{m}^{-1} \mathrm{~s}^{-1}\right)$.

$\rho$ : $\quad$ Fluid density $\left(\mathrm{kg} \mathrm{m}^{-3}\right)$

$\tau$ : $\quad$ Shearing stress $(\mathrm{P}$ a)

$g$ : Gravitational acceleration $\left(\mathrm{m} \mathrm{s}^{-2}\right)$

$\xi: \quad$ Magnetic force parameter

$\beta$ : $\quad$ Volumetric thermal expansion $\left(\mathrm{K}^{-1}\right)$

$\lambda$ : Richardson number

$v_{m}:$ Magnetic permeability $\left(\mathrm{H} \mathrm{m}^{-1}\right)$

$\theta$ : Dimensionlized temperature

$\alpha: \quad$ Thermal diffusivity $\left(\mathrm{m}^{2} \mathrm{~s}^{-1}\right)$

$\gamma: \quad$ Magnetic Prandtl number
T: $\quad$ Temperature of the fluid $(\mathrm{K})$

Pr: Prandtl number

$\Omega$ : Porous medium parameter.

\section{Data Availability}

The data used to support the findings of this study are available from the corresponding author upon request.

\section{Conflicts of Interest}

The authors declare that they have no conflicts of interest regarding the publication of this paper.

\section{Acknowledgments}

The authors extend their appreciation to the Deanship of Scientific Research at Majmaah University for funding this work under the project number (RGP-2019-6).

\section{References}

[1] Y. Joshi and B. Gebhart, "Mixed convection in porous media adjacent to a vertical uniform heat flux surface," International Journal of Heat and Mass Transfer, vol. 28, no. 9, pp. 17831786, 1985.

[2] M. A. Hossain, N. Banu, D. A. S. Rees, and A. Nakayama, "Unsteady force convection boundary layer flow through a saturated porous medium," in Proceedings of the International Conference on Porous Media and Their Applications in Science, pp. 85-101, Engineering and Industry, Washington, DC, USA, October 1996.

[3] A. J. Chamkha, "Mixed convection flow along a vertical permeable plate embedded in a porous medium in the presence of a transverse magnetic field," Numerical Heat Transfer, Part A: Applications: An International Journal of Computation and Methodology, vol. 34, no. 1, pp. 93-103, 2007.

[4] A. Chamkha, R. S. R. Gorla, and K. Ghodeswar, "Non-similar solution for natural convective boundary layer flow over a sphere embedded in a porous medium saturated with a nanofluid," Transport in Porous Media, vol. 86, no. 1, pp. 13-22, 2011.

[5] R. Nazar, L. Tham, I. Pop, and D. B. Inghum, "Mixed convection boundary layer flow from a horizontal circular cylinder embedded in a porous medium filled with a nanofluid," Transport Porous Media, vol. 86, no. 1, pp. 517-536, 2011.

[6] R. S. R. Gorla, A. J. Chamkha, and A. M. Rashad, "Mixed convective boundary layer flow over a vertical wedge embedded in a porous medium saturated with a nanofluid: natural convection dominated regime," Nonoscale Research Letters, vol. 6, no. 207, pp. 2-9, 2011.

[7] D. S. Cimpean and I. Pop, "Fully developed mixed convection flow of a nanofluid through an inclined channel filled with a porous medium," International Journal of Heat and Mass Transfer, vol. 55, no. 4, pp. 907-914, 2012.

[8] S. M. Imran, S. Asghar, and M. Mushtaq, "Mixed convection flow over an unsteady stretching surface in a porous medium with heat source," Mathematical Problems in Engineering, vol. 2012, pp. 1-15, Article ID 485418, 2012.

[9] G. F. Al-Sumaily and M. C. Thompson, "Forced convection from a circular cylinder in pulsating flow with and without the 
presence of porous media," International Journal of Heat and Mass Transfer, vol. 61, no. 1, pp. 226-244, 2013.

[10] T. Hayat, S. A. Shehzad, M. Qasim, and A. Alsaedi, "Mixed convection flow by a porous sheet with variable thermal conductivity and convective boundary condition," Brazilian Journal of Chemical Engineering, vol. 31, no. 1, pp. 109-117, 2014.

[11] T. Behzadi, K. M. Shirvan, S. Mirzakhanlari, and A. A. Sheikhrobat, "Numerical simulation on effect of porous medium on mixed convection heat transfer in a ventilated square cavity," Procedia Engineering, vol. 127, no. 1, pp. 221-228, 2015.

[12] I. Ullah, S. Shafie, and I. Khan, "MHD Mixed convection flow of Casson fluid over a moving wedge saturated in a porous medium in the presence of chemical reaction and convective boundary conditions," Journal of Science and Technology, vol. 9, no. 3, pp. 131-139, 2017.

[13] S. L. Yadav and A. K. Singh, "Transient flow in a circular cylinder filled with porous material," International Journal of Applied and Computational Mathematics, vol. 4, no. 145, pp. 1-13, 2018.

[14] M. Ashraf and A. Fatima, "Numerical simulation of the effect of transient shear stress and rate of heat transfer around different position of sphere in the presence of viscous dissipation," Journal of Heat Transfer, vol. 140, no. 6, pp. 1-12, 2018.

[15] P. Garg, G. N. Purohit, and R. C. Chaudhary, "Free-convective unsteady MHD flow in slip-flow regime past a vertical plate with a convective surface boundary condition," Journal of Informatics and Mathematical Sciences, vol. 10, no. 1-2, pp. 261-270, 2018.

[16] M. Ashraf, U. Ahmad, and A. J. Chamkha, "Computational analysis of natural convection flow driven along a curved surface in the presence of exothermic catalytic chemical reaction," Computational Thermal Sciences: An International Journal, vol. 11, no. 4, pp. 339-351, 2019.

[17] M. Ashraf, A. Khan, and R. S. R. Gorla, "Natural convection boundary layer flow of nanofluids around different stations of the sphere and into the plume above the sphere," Heat Transfer-Asian Research, vol. 48, no. 3, pp. 1127-1148, 2019.

[18] A. M. Rashad, W. A. Khan, S. M. M. El-Kabeir, and A. M. A. El-Hakiem, "Mixed convective flow of micropolar nanofluid across a horizontal cylinder in saturated porous medium," Applied Sciences, vol. 9, no. 23, p. 5241, 2019.

[19] A. A. A. A. Al-Rashed, G. A. Sheikhzadeh, A. Aghaei, F. Monfared, A. Shahsavar, and M. Afrand, "Effect of a porous medium on flow and mixed convection heat transfer of nanofluids with variable properties in a trapezoidal enclosure," Journal of Thermal Analysis and Calorimetry, vol. 139, no. 1, pp. 741-754, 2020.

[20] M. Ashraf and Z. Ullah, "Effects of variable density on oscillatory flow around a non- conducting horizontal circular cylinder," AIP Advances, vol. 10, no. 1, pp. 015-020, 2020.

[21] Z. Ullah, M. Ashraf and A. M. Rashad, Magneto-thermo analysis of oscillatory flow around a non-conducting horizontal circular cylinder," Journal of Thermal Analysis and Calorimetry, 2020.

[22] Z. Ullah, M. Ashraf, S. Zia, Y.-M. Chu, I. Khan, and K. Sooppy Nisar, "Computational analysis of the oscillatory mixed convection flow along a horizontal circular cylinder in thermally stratified medium," Computers, Materials \& Continua, vol. 65, no. 1 , pp. 109-123, 2020. 